\title{
Remission induced by an elemental diet in small bowel Crohn's disease
}

\author{
I R SANDERSON, S UDEEN, P S W DAVIES, M O SAVAGE, AND J A WALKER-SMITH \\ Department of Child Health, St Bartholomew's Hospital, London
}

SUmmary Seventeen children with active Crohn's disease of the small intestine were entered into a randomised control trial comparing the efficacy of an elemental diet with that of a high dose steroid regimen. Eight children received an elemental diet (Flexical) through a nasogastric tube for six weeks, followed by reintroduction of food over six weeks during which the Flexical was stopped. Seven children were given intramuscular adrenocorticotrophic hormone followed by oral prednisolone with sulphasalazine. Two children were withdrawn from the trial. The elemental diet was equally effective in inducing an improvement in Lloyd-Still disease activity index, erythrocyte sedimentation rate, $\mathrm{C}$ reactive protein and albumin concentrations, and body weight as the high dose steroid regimen. Linear growth, assessed from height velocity over six months, was significantly greater in the children receiving an elemental diet.

Treatment with high dose steroids is the conventional treatment for inducing a remission in Crohn's disease both in adults ${ }^{1}$ and in children. ${ }^{2}$ Enteral nutrition with elemental diets where nutrients are

Table 1 Age, sex, pubertal state, and sites of bowel inflammation of the cases on entry into the trial

\begin{tabular}{llll}
\hline $\begin{array}{l}\text { Case } \\
\text { No }\end{array}$ & $\begin{array}{l}\text { Bgene } \\
\text { age }\end{array}$ & Sex & $\begin{array}{l}\text { Stage of } \\
\text { puberty } \\
\text { (and after } \\
\text { six months) }+\end{array}$
\end{tabular}

\begin{tabular}{|c|c|c|c|c|c|}
\hline \multicolumn{6}{|c|}{ Group treated with steroids } \\
\hline 1 & $13 \cdot 0$ & $9 \cdot 1$ & $\mathbf{M}$ & $2(2)$ & Ileum \\
\hline 2 & $12 \cdot 7$ & $12 \cdot 3$ & $\mathbf{M}$ & $1(3)$ & Ileum, caecum \\
\hline 3 & $14 \cdot 4$ & $14 \cdot 7$ & $\mathbf{M}$ & 5 & Ileum \\
\hline 4 & $16 \cdot 3$ & & $\mathrm{~F}$ & 5 & Ileum, caecum \\
\hline 5 & $14 \cdot 4$ & $11 \cdot 6$ & $\mathbf{M}$ & $2(3)$ & Ileum \\
\hline 6 & $11 \cdot 9$ & $13 \cdot 2$ & $\mathbf{M}$ & $3(5)$ & $\begin{array}{l}\text { Ileum, transverse } \\
\text { colon }\end{array}$ \\
\hline 7 & $10 \cdot 3$ & $9 \cdot 2$ & $\mathbf{M}$ & $1(1)$ & Ileum. caecum \\
\hline 8 & $8 \cdot 6$ & $8 \cdot 4$ & $\mathrm{~F}$ & $1(1)$ & Ileum \\
\hline \multicolumn{6}{|c|}{ Group fed elemental diet } \\
\hline 1 & $12 \cdot 7$ & $9 \cdot 3$ & $\mathbf{F}$ & $1(1)$ & Ileum \\
\hline 2 & $13 \cdot 3$ & $11 \cdot 2$ & $\mathbf{M}$ & $2(4)$ & $\begin{array}{l}\text { Jejunum, ileum. } \\
\text { caecum }\end{array}$ \\
\hline 3 & $11 \cdot 2$ & $10 \cdot 6$ & $\mathbf{M}$ & $1(1)$ & Jejunum, ileum \\
\hline 4 & $12 \cdot 8$ & $13 \cdot 4$ & $\mathbf{M}$ & $1(2)$ & Ileum \\
\hline 5 & 11.4 & $13 \cdot 3$ & $\mathrm{~F}$ & $1(2)$ & Ileum \\
\hline 6 & $17 \cdot 2$ & & $\mathbf{M}$ & 5 & Ileum, rectum \\
\hline 7 & $12 \cdot 7$ & $9 \cdot 7$ & $\mathrm{~F}$ & $1(1)$ & Ileum, colon \\
\hline 8 & $14 \cdot 5$ & $14 \cdot 5$ & $\mathbf{M}$ & $2(3)$ & Ileum \\
\hline 9 & $16 \cdot 0$ & $15 \cdot 3$ & $\mathbf{M}$ & 5 & Ileum \\
\hline
\end{tabular}

*Withdrawn from the trial.

† Stage of puberty is expressed as genitalia stage in boys and breast stage in girls. supplied free of intact protein (nitrogen being supplied by amino acids and oligopeptides) has also been used for both adults ${ }^{3}$ and children. ${ }^{5} 6$ Such specific nutritional treatment has usually been reserved for the complex case and is often used as an adjunct to treatment with steroids.

Growth retardation has been recognised as an important clinical feature from the time of the first descriptions of Crohn's disease in children. ${ }^{78}$ It is also a well recognised complication of treatment with steroids in children. ${ }^{9}$ In the doses required to induce a remission in children with Crohn's disease, steroids also often produce Cushingoid features. The use of elemental diets is not associated per se with such complications and healthy volunteers have been maintained on them for long periods. ${ }^{10}$

As there has been no study comparing the relative effects of an elemental diet and steroids to induce a remission in Crohn's disease of the small intestine in children a study was undertaken to compare these two therapeutic regimens in relation to their ability to induce a remission by standard criteria. The opportunity was also taken to compare the effect of linear growth of these two modes of treatment.

\section{Patients}

Seventeen children, 12 boys and five girls, aged from 8.6 to 17.2 years, were studied at our hospital (Table 1). Seven of the children were prepubertal and 10 pubertal. Patients attending the paediatric 
inflammatory bowel disease clinic were entered into the trial if they satisfied the following criteria:

(i) Crohn's disease of the small bowel shown by barium follow through and confirmed by ileal histology of endoscopic biopsy specimens.

(ii) Clinical relapse of sufficient severity to warrant treatment with high dose steroids.

(iii) No treatment with steroids for the previous 12 months.

(iv) Incomplete skeletal maturation.

(v) Domiciled in England (to facilitate follow up).

\section{Methods}

Auxological assessment. All the patients underwent measurements of stature by a trained clinical auxologist according to the method of Cameron. ${ }^{11}$ Pubertal development was assessed using the criteria of Tanner. ${ }^{12}$ Bone age was assessed by the same observer using the TW2-RUS method. ${ }^{12}$

Treatment regimens. The subjects (Table 1) were randomly allocated to receive either treatment with drugs (high dose steroids and sulphasalazine) or dietetic treatment as an elemental diet. (Both forms of treatment were explained to both parents and children. Informed consent was obtained and any child withdrawn from the trial was to be given treatment with drugs.)

All children were admitted to hospital for one week. The first group received high dose steroids given as adrenocorticotrophic hormone (2 IU $/ \mathrm{kg} /$ day) intramuscularly for five days followed by oral prednisolone $(2 \mathrm{mg} / \mathrm{kg} /$ day to a maximum of 30 $\mathrm{mg} / \mathrm{day}$ ). They were also started on sulphasalazine $(50 \mathrm{mg} / \mathrm{kg} / \mathrm{day}){ }^{2}$ No specific dietetic advice was given as this is the usual practice in such children.

The second group was treated with an elemental diet, Flexical (Table 2) by nasogastric tube. They were otherwise given nothing by mouth. The daily energy requirement of a particular child was determined using the recommended daily allowance ${ }^{13}$ based on his age and weight. As the energy content of Flexical is $4.2 \mathrm{~kJ} / \mathrm{ml}$ the total daily volume of feed could be calculated. The rate of infusion was adjusted so that a child could take the feed in the evening and overnight and so attend school. In the ward the concentration of the diet was built up to full strength over four days. Patients were taught how to pass a fine bore nasogastric tube, which was changed at home at least once a week. (Sulphasalazine was continued in two children who were receiving this drug at the start of the study but otherwise was not given to this group.)

After one week in hospital the children were managed as outpatients. The dose of steroids was gradually reduced after three weeks in the steroid group, aiming for an alternate day regimen of $10 \mathrm{mg}$ by 12 weeks. Foods were individually introduced after six weeks in those receiving elemental diet, a new food being introduced every four days (Table 3 ). The energy content of the new foods taken was monitored every two weeks by a dietitian, who reduced the elemental diet accordingly. The Flexical was always stopped by six weeks after the start of the food reintroduction.

Table 2 Composition of Flexical (per litre of full strength formula)

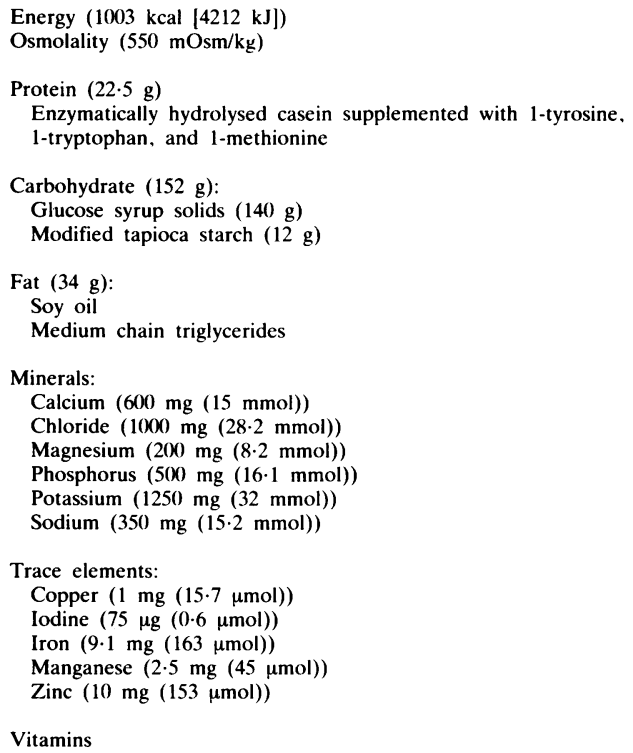

Vitamins

Table 3 Food reintroduction programme six weeks after starting Flexical

Each new food is reintroduced into the diet four days after the previous food in the following order:

Potatoes

Lamb

Pears

Chicken

Yeast (Breweres Yeast Tablets)

Wheat (spaghetti)

Bread (wholemeal)

Cabbage

Rice

Apple

Carrot

Beef

Milk

Butter

Cheese

Eggs

A free diet is allowed once these foods have been started 
Assessment. Disease activity was assessed using the Lloyd-Still disease activity index score ${ }^{14}$ composed of the clinical history, physical examination, packed cell volume, white blood cell count, serum albumin concentration, erythrocyte sedimentation rate (ESR), and appearances on barium meal and follow through examination. Serum $\mathrm{C}$ reactive protein concentration was also measured. Colonoscopy and ileoscopy were performed with barium examination only at entry into the study. Disease activity was assessed at 0,6 , and 12 weeks and the change at 6 and 12 weeks calculated.

Linear growth was assessed from the heights of the children at entry into the study and six months later. The results are expressed as height velocity standard deviation score for chronological age. ${ }^{15}$

Statistics. Comparison between groups at entry into the trial and the changes from baseline values with treatment were assessed using the Student's $t$ test for Lloyd-Still disease activity index, ESR, albumin and $C$ reactive protein concentrations, and body weight. Linear growth was compared in the two groups by the Mann-Whitney test.

\section{Results}

Two children were withdrawn from the trial. One child (case 4 in the group treated with steroids) developed clinical features of intestinal obstruction and underwent bowel restriction two weeks after beginning treatment with steroids. One child (case 6 in the group fed the elemental diet) was unwilling to forego a normal diet. He was treated with high dose steroids.

There were no significant differences in the two groups on entry into the trial with regard to sex distribution, age, disease activity, height standard deviation score, ESR, and $\mathrm{C}$ reactive protein or albumin concentrations (Table 4). Pubertal state was also similar in the two groups.

Table 4 Clinical features at entry into the trial of the two groups of children who completed the study. Values are mean (SEM)

\begin{tabular}{lll}
\hline & \multicolumn{2}{l}{ Group } \\
\cline { 2 - 3 } & High dose steroids & Elemental diet \\
\hline Sex (M/F) & $6 / 1$ & $5 / 3$ \\
Age (years) & $12 \cdot 2$ & $13 \cdot 1$ \\
Lloyd-Still disease activity (\%) & $61(3)$ & $56(4)$ \\
Height standard deviation score & $-1 \cdot 0(1 \cdot 0)$ & $-1 \cdot 1(1 \cdot 9)$ \\
Erythrocyte sedimentation rate & $32(6)$ & $37(3)$ \\
$\quad$ (mm in the first hour) & $40(11)$ & $43(10)$ \\
C reactive protein (mg/l) & $37(4)$ & $32(2)$ \\
Albumin (g/l) & & \\
\hline
\end{tabular}

The mean and standard error of the changes in disease activity, ESR, $C$ reactive protein and serum albumin concentrations, and weight were calculated for each treatment regimen (Table 5). The disease activity of the children improved significantly $(p<0.01)$ by six weeks with both elemental diet and high dose steroids. The improvement in disease activity index, ESR, $C$ reactive protein and albumin concentrations, or weight of those on elemental diet was of similar magnitude to those on high dose steroids (Table 5). In both groups the ESR and the $\mathrm{C}$ reactive protein concentration had fallen into the normal range by six weeks, and the children were therefore biochemically in remission. Moreover, at 12 weeks, when the elemental diet group had already finished the Flexical regimen but the steroid group was still taking a mean of $10 \mathrm{mg} /$ day prednisolone, this improvement was maintained (Table 5).

Mean height velocity for chronological age (Figure) was significantly greater $(\mathrm{p}<0.05)$ in the elemental diet group than in the steroid group, despite similar gain in weight. Six children in the elemental diet group had a positive height velocity standard deviation score, indicating supranormal growth, compared with only one in the steroid group.

It is not possible to say whether the height velocity data are part of a normal distribution as there are different factors affecting the growth at one time, such as disease activity, pubertal state, steroid dosage, and energy intake. The data were therefore compared using the Mann-Whitney test.

\section{Discussion}

This paper shows for the first time that in children an elemental diet is as effective as high dose steroids in treating Crohn's disease of the small bowel. No

Table 5 Changes in Lloyd-Still disease activity index score, erythrocyte sedimentation rate ( $E S R), C$ reactive protein, albumin, and weight over six and 12 weeks after the start of treatment. Values are mean $(S E)$

\begin{tabular}{|c|c|c|c|}
\hline & \multirow{2}{*}{$\begin{array}{l}\text { Weeks from } \\
\text { start of } \\
\text { treatment }\end{array}$} & \multicolumn{2}{|l|}{ Group } \\
\hline & & $\begin{array}{l}\text { High dose } \\
\text { steroids }\end{array}$ & Elemental diet \\
\hline \multirow[t]{2}{*}{ Score } & 6 & $17(3)$ & $22(2)$ \\
\hline & 12 & $19(4)$ & $22(3)$ \\
\hline \multirow{3}{*}{$\begin{array}{l}\text { Erythrocyte sedimen- } \\
\text { tation rate ( } \mathrm{mm} \text { in } \\
\text { the first hour) }\end{array}$} & & & \\
\hline & 6 & $-22(5)$ & $-23(3)$ \\
\hline & 12 & $-20(6)$ & $-20(7)$ \\
\hline \multirow{2}{*}{$\begin{array}{l}\mathrm{C} \text { reactive protein } \\
(\mathrm{mg} / \mathrm{l})\end{array}$} & 6 & $-30(8)$ & $-37(10)$ \\
\hline & 12 & $-30(8)$ & $-32(9)$ \\
\hline \multirow[t]{2}{*}{ Albumin $(\mathrm{g} / \mathrm{l})$} & 6 & $4(2)$ & $1 \cdot 0(4)$ \\
\hline & 12 & $13(4)$ & $10(4)$ \\
\hline \multirow[t]{2}{*}{ Weight (kg) } & 6 & $4 \cdot 7(1.7)$ & $3 \cdot 0(0 \cdot 7)$ \\
\hline & 12 & $7 \cdot 6(2 \cdot 5)$ & $5 \cdot 5(0.9)$ \\
\hline
\end{tabular}




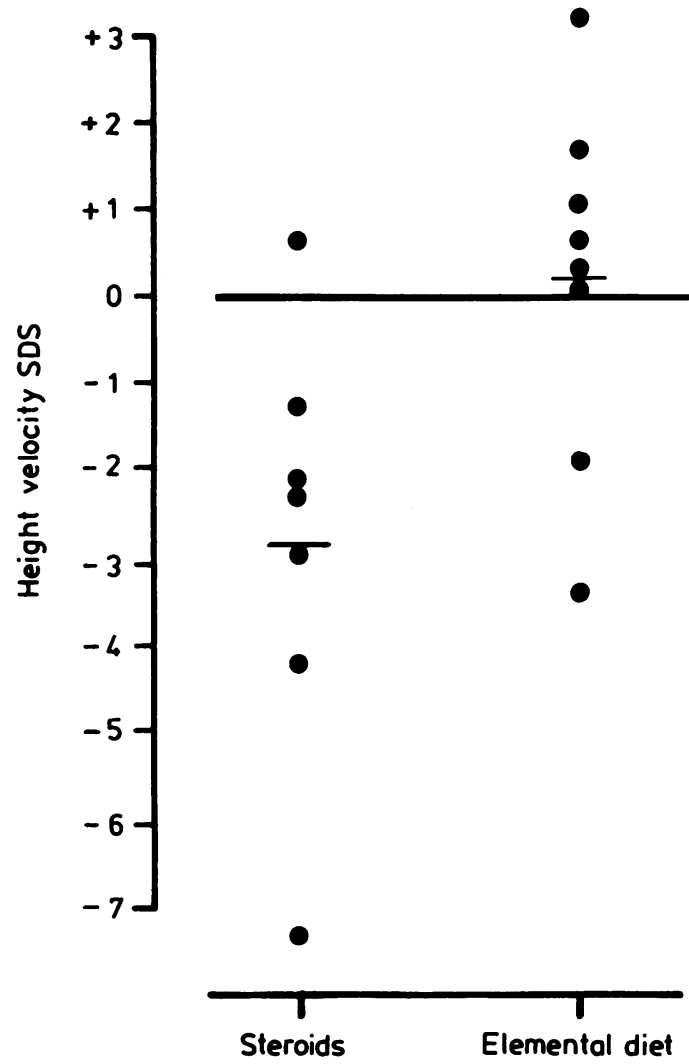

Figure Height velocity standard deviation score (SDS) for chronological age in the children in the high dose steroid group (mean -2.8) and in the elemental diet group (mean $+0 \cdot 3)$.

previous study in children has used a control group for comparison. ${ }^{61617}$ The only control trial of elemental diet to date was performed in patients in whom the disease presented long after adult height had been achieved. ${ }^{3}$ Moreover, this is also the first study in which the diagnosis has been confirmed in all cases on strict histological criteria. ${ }^{18} \mathrm{~A}$ further feature of the present study is that the duration of hospital stay was the same in both groups, which eliminates bias caused by the possible beneficial effects of bed rest on the activity of Crohn's disease.

Flexical, used in this study because of its adequate zinc content and appropriately low sodium content, is a complete feed in which nitrogen is supplied in the form of amino acids and oligopeptides. The term elemental was adopted to describe the Mead Johnson 3200 AS formula, the prototype for Flexical. Some workers in Europe have used a new term, semi-elemental, to describe diets that contain oli- gopeptides as well as amino acids; this usage has not been adopted, however, in North America or the United Kingdom. Like other elemental diets Flexical is free of dietary antigens, which may explain its beneficial effect. A change in diet could produce subtle changes, though, in the microflora of the small intestine.

It has been suggested that the immunological reactions that may propagate the inflammation in Crohn's disease are altered by increased energy intake. ${ }^{16}$ This is another explanation both for the action of an elemental diet and for high dose steroids as the latter can increase appetite. Measuring energy intake in children who eat at school as well as at home is unreliable and was not attempted in the present study. In addition, as routine dietary advice is not part of current drug treatment any attempt to quantify energy intake accurately would be likely to distort the simple effect of drugs alone.

The unpalatability of the elemental diet was avoided by administering it through a nasogastric tube. All children were taught to pass their own tubes so that those who wished to remove them to avoid embarrassment during school hours could do so. No child was given the opportunity of drinking the diet as an alternative, as previous experience with this method had led to poor compliance. Being unable to eat normal food for six weeks was unacceptable to one child, however, who was therefore not studied.

Linear growth was greater in the subjects treated by elemental diet, but the variety of factors that affect growth make it impossible to say whether or not this was due to active suppression of growth by the steroid regimen. ${ }^{9}$ Expression of height velocity in standard deviation scores for chronological age is valid as there is poor correlation of bone age with height velocity in the adolescent growth spurt. There was also no significant difference in the mean delay in bone age between the two groups (Table 1).

In conclusion, treatment by elemental diet is equally effective in inducing remission in Crohn's disease of the small bowel as high dose steroids in children. Moreover, linear growth was significantly greater in those taking an elemental diet, indicating that there is a short term benefit for growth. The long term results of this treatment still need to be evaluated. A recent study of height attainment in children with steroid responsive nephrotic syndrome showed that, while large doses of steroids suppressed growth at the time of administration, there was little effect on ultimate height. ${ }^{19}$ This favourable result has not been reproduced, however, in children with Crohn's disease on current treatment. A long term follow up study of 66 children under 16 with small bowel disease who had been treated with 
steroids revealed that 20 were at or below the third centile two to 14 years later. ${ }^{20}$

We believe that an elemental diet is the initial treatment of choice in children with Crohn's disease of the small intestine, and since completing this study we have used it as standard treatment at our hospital.

Dr Sanderson is grateful to the Crohn's in Childhood Research Appeal for their support.

\section{References}

' Summers RW, Swetz DM, Sessions JT, et al. National cooperative Crohn's disease study: results of drug management. Gastroenterology 1979;77:827-34.

${ }^{2}$ Chong SKF, Bartram C, Campbell CA, Williams CB, Blackshaw AJ, Walker-Smith JA. Chronic inflammatory bowel disease in childhood. $\mathrm{Br}$ Med $J$ 1982;284:101-4.

3 O'Morain C, Segal AW, Levi AJ. Elemental diet as primary treatment of acute Crohn's disease: a controlled trial. $\mathrm{Br}$ Med J 1984;288: 1859-62.

${ }^{4}$ Giorgini GL, Stephens RV, Thayer WR. The use of 'medical bypass' in the therapy of Crohn's disease: report of a case. American Journal of Digestive Diseases 1973;18:153-7.

5 Morin CL, Roulet M, Foy CC, Weber A. Continuous elemental enteral alimentation in children with Crohn's disease and growth failure. Gastroenterology 1980;79:1205-10.

' O'Morain C, Segal AM, Levi AJ, Valman HB. Elemental diet in acute Crohn's disease. Arch Dis Child 1983;53:44-7.

7 Schiff E. Die regionale enteritis. Ann Pediatr (Paris) 1945; 165:281-311.

' O'Donoghue DP, Dawson AM. Crohn's disease in childhood. Arch Dis Child 1977;52:627-32.

${ }^{9}$ Friedman M, Strang LB. Effect of long term corticosteroids and corticotrophin on the growth of children. Lancet 1966;ii:568-72.
10 Winitz M, Graff J, Gallagher N, Narkin A, Seedman DA. Evaluation of chemical as nutrition for man-in-space. Nature 1965;205:741-3.

"Cameron N. The methods of auxological anthropometry. In: Faulkner F, Tanner JM, Human growth. New York: Plenum Press, 1978; 35-87.

12 Tanner JM. The development of the reproductive system. In: Tanner JM. Growth in adolescence. 2nd ed. Oxford: Blackwell 1962; 28-39.

${ }^{13}$ Francis EM. Diets for sick children. Oxford: Blackwell Scientific publications.

14 Lloyd-Still JD, Green OC. A clinical scoring system for chronic inflammatory bowel disease in children. Dig Dis Sci 1979;24:620-5.

15 Tanner JM, Whitehouse RH, Takaishi M. Standards from birth to maturity for height, weight, height velocity, and weight velocity: British children, 1965. Part II. Arch Dis Child 1966;41:613-35.

${ }^{16}$ Morin CL, Roulet M, Weber A, Lapointe N. Continuous elemental alimentation in the treatment of children and adolescents with Crohn's disease. JPEN 1982;6:194-9.

17 Navarro J, Vargas J, Cezard JP, Charritat JL, Polonovski C. Prolonged constant rate elemental enteral nutrition in Crohn's disease. Journal of Pediatric Gastroenterology and Nutrition 1982;1:541-6.

18 Chong SKF, Blackshaw AJ, Boyle S, Williams CB, WalkerSmith JA. Histological diagnosis of chronic inflammatory bowel disease in childhood. Gut 1985;26:55-9.

${ }^{19}$ Foote KD, Brocklebank JT, Meadow SR. Height attainment in children with steroid responsive nephrotic syndrome. Lancet 1985;ii:917-9.

${ }^{20}$ Gryboski JD, Spiro H. Prognosis in children with Crohn's disease. Gastroenterology 1978;74:807-17.

Correspondence to Dr I R Sanderson, Queen Elizabeth Hospital for Children, Hackney Road, London E2 8PS.

Received 9 June 1986 